\begin{abstract}
Recent research has begun to examine discrete caregiver pain management behaviors in the infant immunization context. However, there is a dearth of research exploring more global caregiving constructs, such as emotional availability, which can be used to examine the overall sensitivity of caregiver pain management. The aim of the present study was to examine the relationships between caregiver sensitivity (emotional availability) and infant pain behavior (baseline, immediately post-needle, 1 minute after needle) over the first year of life. Parents and infants were a part of a Canadian longitudinal cohort (The OUCH cohort) followed during their 2-, 4-, 6- and 12-month immunizations (current $\mathrm{n}=731$ ). Both 'within-age' group analyses and 'over-age' analyses were performed. Results indicated that: 1) over age, previous infant pain behavior predicts future infant pain behavior, but this varied depending on timing of pain response and age of infant; 2) over age, previous caregiver sensitivity strongly predicts future caregiver sensitivity; and 3) the concurrent relationship between caregiver sensitivity and every type of infant pain response is only consistently seen at the 12 month immunization. Caregiver sensitivity to the infant in pain is predicted most reliably from previous caregiver sensitivity, not infant pain behaviour. The significant concurrent relationship between caregiver sensitivity and infant pain behaviours is not seen until 12 months, replicating patterns in the infant development literature regarding the time at which the attachment relationship between parent and child can be reliably measured. Discussion addresses implications for both researchers and clinicians who work with infants in pain.
\end{abstract}


The Relationship Between Caregiver Sensitivity and Infant Pain Behaviors Across the First Year

of Life

Rebecca Pillai Riddell ${ }^{\text {a,b,c }}$, Lauren Campbell ${ }^{\text {a }}$, David B. Flora ${ }^{\text {a, Nicole Racine }}{ }^{\text {a }}$, Laila Din

Osmun $^{\mathrm{a}}$, Hartley Garfield ${ }^{\mathrm{b}, \mathrm{c}}$, Saul Greenberg ${ }^{\text {b,c }}$

${ }^{a}$ York University, Toronto Canada

${ }^{b}$ Hospital for Sick Children, Toronto Canada

${ }^{c}$ University of Toronto, Toronto Canada

* Corresponding author: Dr. Rebecca Pillai Riddell. Mailing address: The Opportunities to Understand Childhood Hurt (OUCH) Laboratory, York University, Department of Psychology, Faculty of Health, Room 038J Atkinson College Building, 4700 Keele Street, Toronto, ON, M3J 1P3 Phone: 416-736-2100 x 20177 Fax: 416-736-5814 Email address: rpr@yorku.ca URL: http://www.yorku.ca/ouchlab/index.html

Number of text pages of entire manuscript (including figures and tables): 26

Number of figures and tables: 3 figures, 6 tables 


\title{
The Relationship Between Caregiver Sensitivity and Infant Pain Behaviors Across the First Year
}

\author{
of Life
}

\section{Introduction}

The integral role of the caregiver in shaping the expression of distress and regulation $[3,15,32,34,35,37]$ has recently begun to be established in the infant pain immunization context [36]. While certain behaviors such as distraction [7,8,16,19], non-procedural talk [28], displays of positive affect [19], and proximal soothing such as rocking, touching, stroking, kissing, and maternal vocalizations $[11,24,27,36]$ have been associated with lower levels of infant painrelated distress, other caregiver behaviors such as apologizing [7,13], empathizing [7,13], and verbal reassurance $[39,7,13]$ have been associated with higher levels of infant pain-related distress.

However, from an infant mental health perspective, sensitive caregiving in the pain context would be defined as a parent following the changing needs of the infant over the appointment, rather than a sole focus on discrete behaviours [32]. Measures of overall emotional availability or caregiver sensitivity, while limited because one does not track exact behaviors, adds new information by using clinical judgment to assess the overall ability of a specific caregiver to adjust his or her behaviors to the changing needs of his or her specific child. Previous work has suggested that higher sensitivity or emotional availability leads to lower infant pain within an immunization appointment [18]. However, no studies to date have examined how emotional availability and infant pain behaviours relate to each other over development. Analyses of this kind would facilitate taking a broader understanding of an infant's pain behaviour and caregiver's response to those behaviors by also accounting for the relative importance of both previous infant pain behaviour and previous caregiver sensitivity. 
The ultimate purpose of this study is to examine the relationships between caregiver sensitivity and infant pain behavior across the first year of life. The 12-month time frame is important in infant development because it is the time by which the distress regulation patterns between infant and parent are considered stable [3,9]. Infant pain behavior was measured at three different times within an immunization appointment (baseline, needle and 1 minute post needle) across the 4 ages (2, 4, 6 and 12 months). Caregiver sensitivity was assessed for the entire immunization appointment (both before and after needles). The goal was to explore the interrelationships between differently timed infant pain behaviours and parent emotional availability across the first year of life using cross-lagged path analysis. One path analysis was executed for each infant pain outcome. Rather than posit specific hypotheses regarding the 16 coefficients resulting from each of the 3 models ( 48 total), general trends were speculated. It was hypothesized that: 1) In every model (baseline, needle and 1-minute post needle pain $\underline{\text { behaviours), }}$ previous infant pain behavior would positively predict subsequent infant pain behavior; 2) In every model, previous caregiver sensitivity would predict subsequent positively predict caregiver sensitivity; 3 ) In every model, a negative relationship between caregiver sensitivity and infant pain behaviors would be seen and would get stronger as the child ages. Exploratory analyses were also planned to examine whether previous infant pain behavior would predict future caregiver sensitivity and previous caregiver sensitivity would predict future infant pain behavior.

\section{Methods}

\subsection{Study population}

The data from the present study is a part of an ongoing longitudinal cohort (The OUCH Cohort) where caregiver-infant dyads are being recruited from three pediatric clinics in the 
Greater Toronto Area. This longitudinal study recruits infants at 2 months of age and follows them during their 2-, 4-, 6-, and 12-month routine immunization appointments. Caregiver-infant dyads were included in the study if they had been videotaped during any of the immunization appointments. At the time of the present analysis, the total sample size was 731. In terms of number of follow ups, 213 dyads were followed four times (2-,4-,6- and 12-months of age), 256 dyads were followed three times (2-,6-,12- months or 4-,6-,12- months or 2-,4-,6- months), 171 dyads were followed twice (all 2 timepoint permutations were possible) and 91 dyads were followed once (2- or 4- or 6- months). To maximize information used in the analysis, direct maximum likelihood estimation [2] was used so that all cases, including those with incomplete data, contributed to model estimation.

Caregivers able to speak and read English, whose infants had no suspected developmental delays or impairments, chronic illnesses, and had never been admitted to a neonatal intensive care unit were eligible to participate in the study. Table 1 presents demographic variables for the entire sample. At the 2-, 4-, 6-month and 12-month immunization appointments, infants received an average of 2.0 needles ( 2 months $[\mathrm{M}=1.95, \mathrm{SD}=.28] ; 4$ months $[\mathrm{M}=1.95, \mathrm{SD}=.31] ; 6$ months $[\mathrm{M}=1.97, \mathrm{SD}=.33] ; 12$-month appointment $[\mathrm{M}=1.88, \mathrm{SD}$ $=.44]$.

\subsection{Procedure}

The protocol was approved by Research Ethics Boards at both the participating university and associated tertiary level pediatric hospital. Caregivers with infants receiving immunizations were provided a flyer by the medical receptionist and asked if they would like to learn more about a longitudinal study. Caregivers who indicated interest were approached by a research 
assistant (RA). The RA who explained the study's objectives and asked them to sign consent forms. All interested parents agreed to participate upon hearing about the study but only $66.5 \%$ of parents agreed to hear more about the study. Caregivers were informed of the longitudinal nature of the project, that their participation in the study was completely confidential and voluntary, and that they were free to end participation in the study at anytime. The caregiver subsequently completed a demographic information form with the research assistant. Once in the examination room, two video cameras were set up to capture a close-up 'face' shot of the infant as well as a 'wide' shot to obtain a full view of caregiver and child. The research assistant videotaped from the moment the infant entered the examination room up until five minutes after the immunization or when the caregiver and infant had left the clinic room (whichever came first). The research assistant said "now" at the moment when the infant's skin was punctured by the needle to ensure the exact time of the needle was accurately recorded for coding purposes. All infant and caregiver behaviors were coded from this footage (see below for exact epochs). The demographic questionnaire administration and videotaping occurred at each of the four immunization appointments (2-, 4-, 6-, and 12-months of age). After each of the appointments, for the purpose of informed consent (i.e. so parents knew exactly what video information the lab was analyzing) caregivers were mailed a copy of their videotaped immunization appointment. Additionally, families received a postcard reminder and, two weeks before the upcoming appointment, a research assistant phoned the caregiver as a reminder that a research assistant would be at their next immunization appointment to videotape them with their infant. These measures were undertaken as a means of retaining participants and keeping them engaged in the research. The current withdrawal rate is $3 \%$, with the most common reason given 
that they no longer wanted to participate due to lack of interest and second most common reason being that the family was relocating.

\subsection{Apparatus}

Two Canon HD Video Camcorders - HV20 were used to capture caregiver emotional availability and infant pain behaviors. One camera was mounted on a tripod and fitted with a wide-angle lens to capture the caregiver-infant interactions. The second camera used a handheld tripod and a research assistant recorded a close-up image of the infant's face in order to capture infant facial expression.

\subsection{Measures}

\subsubsection{Parent Demographic Information}

Parents were asked to complete a brief demographic questionnaire. The questionnaire contained items regarding personal information, such as relation to the infant, self-reported heritage culture, and education level, as well as information pertaining to the infant, such as infant age, gender, ethnicity, and medical conditions since the last time they participated in the study.

\subsubsection{Infant Pain Behavior}

The Neonatal Facial Coding System (NFCS) [21] was designed to measure infants' facial responses to painful stimuli and is a well-validated assessment tool for acute pain. Based on previous studies [26,29,31], seven indicators (brow bulge, eye squeeze, naso-labial furrow, open lips, vertical stretch mouth, horizontal stretch mouth, taut tongue) were utilized to create a facial pain score. Each of the NFCS facial actions were coded as "0" (not present) or "1" (present) [22] for every second within a 10-second period. The facial pain score was obtained for three specific 10-second periods (see below; NFCS Pre-needle baseline, NFCS Immediate Needle, NFCS 1 
minute) by calculating the proportion of time the NFCS facial actions were present. Scores range from 0 to 1 and indicate the proportion of time during the 10 -second period in which the above facial actions were present. Higher scores indicate greater facial pain expression. Trained NFCS coders were blinded to study hypotheses. Inter-rater reliability was high with percentage agreement scores for all 7 pain facial actions ranging from .85 to .97 .

NFCS was coded during three distinct time periods. First, during the baseline phase which occurred 10 seconds prior to the first needle when there was no pain stimuli (NFCS Baseline Distress); second, during the 10-second period occurring immediately after the last needle (NFCS Immediate Needle or Immediate Reactivity); third, during the 10-second period one minute after the last needle (NFCS 1 Minute or Immediate Regulation).

\subsubsection{Measure of Caregiver Emotional Availability}

Caregiver sensitivity was operationalized by the inclusive construct of emotional availability and was coded using the Infancy/Early Childhood Version of the Emotional Availability Scales-Fourth Edition (EAS) [6]. Rather than using frequency counts of parental behaviors, the EAS is a global clinical judgment of caregiving behavior that is contextualized by the infant's reaction to those behaviors. The total score is a clinical judgment based on detailed objective parameters to determine the quality of the caregiver behaviors. The EAS has been wellvalidated in a variety of distressing non-pain contexts [5] as well as in a pain context [18]. For a parent to have a high EA score, he or she would have to consistently enact behaviors (regardless of what those specific behaviors are) that sensitively and effectively address the infant's painrelated distress.

The EAS examines caregiver behavior on four different subscales: sensitivity, structuring, nonintrusiveness, and nonhostility. A total score is created by combining the four 
subscales to form a composite emotional availability score [5]. Caregiver sensitivity included the caregiver's ability to interpret and respond to the infant's cues while displaying appropriate affect and respecting the developmental level of the infant (e.g. sensitively and contingently responding to the infant's pain cues). Caregiver structuring referred to the caregiver's ability to structure the environment in a manner that leads the infant in a positive direction (e.g. effectively using toys to distract the baby from the pain). Caregiver nonintrusiveness referred to the parent's ability to be available and avoid intrusive, overstimulating, or overpowering behaviors (e.g. getting in the infant's face and intrusively kissing the infant while the infant is highly distressed). Finally, caregiver nonhostility referred to the caregiver's ability to refrain from antagonistic or impatient behaviors (e.g. expressing frustration about the infant's pain-related crying).

The EAS rating was based on video footage from the time the caregiver and infant entered the clinic room until they left. After viewing the entire filmed interaction, a coder provided a rating on each of the Emotional Availability subscales (potential score ranges: 7-29). These subscales were subsequently summed to form a composite EA score on a scale that potentially ranges from 28 to 116 . On all scales, higher scores represented more optimal interactions. When more than one caregiver accompanied the infant for the immunization appointment the caregiver who did the majority of the caregiving was coded. When both caregivers provided equal care during the clinic visit, both caregivers were coded and an average was obtained.

Coders undertook reliability training with the scale's designer, Dr. Zeynep Biringen. Four coders coded the videotaped immunization appointments for this study and were blind to study hypotheses. Inter-rater reliability was calculated among every permutation of the four coders (e.g. coder A with B, B with C, A with D, etc.). Intraclass correlations for the caregiver EAS 
composite score ranged from .88 - .93. In addition, five percent of the total sample was quadruple coded by all coders to prevent coder drift and the intraclass correlations for the caregiver EAS composite score was .93 .

\section{Results}

An auto-regressive cross-lagged path model (e.g., [25]) was fitted to the data using structural equation modeling software. This model included parameters such that for both caregiver sensitivity (EAS) and infant pain variables (NFCS), three types of relationships were examined simultaneously: 1) The prediction of each infant pain score (or caregiver sensitivity score) from the pain score (or caregiver sensitivity score) that directly preceded it (e.g. infant pain at 2 months predicting infant pain at 4 months); 2) The prediction of each infant pain score (or sensitivity score) from the caregiver sensitivity score (or infant pain score) that directly preceded it (e.g. infant pain at 2 months predicting caregiver sensitivity at 4 months); and 3) The concurrent residual relationships between infant pain and caregiver sensitivity at each of the four ages (e.g. infant pain at 2 months with caregiver sensitivity at 2 months). Three separate path models were estimated (see Figures 1, 2 and 3) for each of the different infant pain response variables (baseline, needle, 1-minute post-needle). The Yuan-Bentler [41] model chi-square statistic and robust standard errors were used to account for potential non-normality in the presence of missing data. Following standard reporting procedure for this statistical technique, Table 2 and Table 3 presents the overall means and standard deviations of all model variables along with standard bi-variate correlations among these variables. Description and discussion of the proposed models follow.

\subsection{Primary analyses}




\subsubsection{Model 1: Examining the relationships among caregiver sensitivity and baseline NFCS scores across the first year of life (See Table 4 and Figure 1).}

Although the chi-square test of overall model fit was significant $\left(\chi^{2}=90.19, p<.001\right)$, the standardized root mean squared residual was good $(\mathrm{SRMR}=.08 ;[42])$, which indicates that the model has reproduced the correlations among these variables well. Complete unstandardized results for this model are in Table 4, while Figure 1 gives the corresponding path diagram (along with standardized parameter estimates for ease of relative interpretation). The autoregressive relationships for NFCS baseline scores are all non-significant ( $p \mathrm{~s}>.05)$, with the exception that scores at 4 months predicted scores at 6 months $(b=.16 ; p<.05)$. For EAS, the autoregressive relationships are generally moderate, with the magnitude of the relationship getting larger across the year (2-month EAS to 4-month EAS $b=.40, p=.00 ; 4$-month EAS to 6-month EAS $b=.54$, $p=.00 ; 6$-month EAS to 12-month EAS $b=.62, p=.00)$. The cross-lagged relationships between baseline NFCS and EAS were consistently weak and non-significant ( $p s>.05)$, indicating that the prior baseline NFCS scores do not predict the directly following EAS scores, nor do the prior EAS scores predict the following NFCS scores. Finally, there were significant concurrent negative residual correlations between NFCS baseline and EAS at both four $(r=-.24)$ and 12 months ( $r=-.23$; both $p s<.001$; unstandardized), while the concurrent residual correlations were small and non-significant at both two months and six months (both $p \mathrm{~s}>.05$ ).

\subsubsection{Model 2: Examining the relationships between caregiver sensitivity and NFCS needle scores across the first year of life (See Figure 2 and Table 5).}

Although the chi-square test of overall model fit was significant $\left(\chi^{2}=79.93, p<.001\right)$, the standardized root mean squared residual was good (SRMR $=.089 ;[41])$, which indicates that 
the model has reproduced the correlations among these variables well. Complete unstandardized results for this model are in Table 5, while Figure 2 gives the corresponding path diagram (along with standardized parameter estimates). The autoregressive relationships for NFCS needle scores, respectively, were all significant $(p \mathrm{~s}>.00 ; b=.41, b=.33)$, with the exception that scores at 6 months did not predict scores at 12 months $(p>.05)$. For EAS, the autoregressive relationships were generally moderate, with the magnitude of the relationship getting larger $\underline{\text { across }}$ the year (2-month EAS to 4-month EAS $b=.41, p=.00 ; 4$-month EAS to 6-month EAS $b=.55, p=.00 ; 6$-month EAS to 12-month EAS $b=.62, p=.00)$. The cross-lagged relationships between needle NFCS needle and EAS were consistently weak and non-significant ( $p$ s > .05), indicating that the prior needle NFCS scores do not predict the following EAS scores, nor does the prior EAS scores predict the following NFCS needle scores. Finally, there was a significant concurrent negative residual correlation between NFCS needle and EAS at 12 months $(r=-.33$, $\mathrm{p}<.00$; unstandardized), while the concurrent residual correlations were small and nonsignificant at two-, four- and six-months ( $p$ s > .05).

\subsubsection{Model 3: Examining the relationships between caregiver sensitivity and NFCS 1 minute} post needle (See Figure 3 and Table 6).

Although the chi-square test of overall model fit was significant $\left(\chi^{2}=90.19, p<.000\right)$, the standardized root mean squared residual was good (SRMR $=.095 ;[41])$, which indicates that the model has reproduced the correlations among these variables well. Complete unstandardized results for this model are in Table 6, while Figure 3 gives the corresponding path diagram (along with standardized parameter estimates). The autoregressive relationships for NFCS 1-minute scores were all significant $(p s<.05)$ or approaching significance $(2$-month 1-minute NFCS to 4month 1-minute NFCS $b=.12, p=.01 ; 4$-month 1-minute NFCS to 6-month 1-minute NFCS $b=$ 
$.08, p=.08 ; 6$-month 1-minute NFCS to 12-month 1-minute NFCS $b=.13, p=.04)$. For EAS, the autoregressive relationships were generally moderate, with the magnitude of the relationship getting larger across the year (2-month EAS to 4-month EAS $b=.40, p=.00 ; 4$-month EAS to 6 -month EAS $b=.55, p=.00 ; 6$-month EAS to 12-month EAS $b=.62, p=.00$ ). The crosslagged relationships between NFCS 1-minute and EAS were generally weak and non-significant $(p s>.05)$, indicating that the prior 1-minute NFCS scores do not predict the following EAS scores, nor vice versa. However, there was one exception in that 2-month NFCS 1-minute scores did predict 4-month EAS scores $(b=.12, \mathrm{p}=.01)$. Finally, there was also a significant concurrent negative residual correlations between 12-month NFCS 1-minute and EAS at 12 months $(r=-.39, \mathrm{p}<.00$; unstandardized), while the concurrent residual correlations were small and non-significant at two-, four- and six-months ( $p$ s > .05).

\section{Discussion}

The present study explored a transactional model of caregiver emotional availability (sensitivity) and infant pain behavior in an infant immunization context. The relationship between infant pain behaviors and caregiver emotional availability was examined across the year, separately running analyses for baseline pain scores, needle pain scores (immediately after needle) and 1 minute pain scores (60 seconds after needle). Hypotheses were partially confirmed, as previous infant pain behavior did partially predict forward, previous caregiver sensitivity did predict forward and the concurrent relationship between caregiver sensitivity and pain behavior was consistently strongest at 12 months. However, interrelationships did differ according to the type of pain response (baseline, needle and 1-minute). 
First, the most integrative analyses examined the concurrent and predictive relationships between caregiver sensitivity and infant pain behaviors across the first year of life. The only consistent significant relationships between caregiver sensitivity and infant pain behaviors (among baseline, needle and 1-minute post needle) occurred at 12-months of age (although there were two other significant relationships noted: at 4-months, baseline pain behavior and caregiver sensitivity was concurrently related; 1 minute pain scores at 2-months predicted caregiver sensitivity at 4-months)._All significant concurrent relationships were negative, suggesting that more sensitive the caregiver the lower the infant pain scores. This suggests that a direct relationship between these variables may not reliably manifest itself until the child is 1 year of age. These findings are in line with the infant mental health literature that suggests the primary caregiver-infant relationship is not reliably measured until 12 months of age [1] and that while caregiver sensitivity is a significant predictor of how an infant uses the caregiver to regulate distress, there are other factors that need to be determined [17].

Second, the relationship of caregiver sensitivity across the four timepoints was demonstrated to be strong and getting larger as the child ages, suggesting an increasing stability of parental sensitivity across the first year of life. Given the magnitude of the relationships across the time period of when their child is 2 and 12 months of age, a relatively large piece of the variability in caregiver sensitivity seems to be dictated by how the caregiver starts out at 2 months. In the immunization pain context, this may imply that early intervention is important and that caregivers should be taught proper pain management strategies even before the 2-month immunization, as this optimal level of soothing will be carried forward through the year of life in which infants receive the most immunizations. 
Finally, very interestingly, the ability of infant pain behaviors to predict forward across the first year of life varied significantly depending on the timing of the pain measure. The baseline infant pain scores only predicted forward between four and six months, while the needle pain scores predicted forward among the 2-, 4- and 6-month time points (at almost double the magnitude) and the 1-minute pain scores predicted forward between 2 and 4 months and 6 and 12 months (with the relationship between 4 and 6 months just missing significance at $\mathrm{p}=.076$ ). Given the varying patterns, it is challenging to speculate reasons for these findings. However, given the substantial sample size, a few interpretative points can be made. It appears that an infant's reaction immediately after the needle is closely related at 2, 4 and 6 months, perhaps suggesting that early pain reactivity may be partially dependent on a factor that is not initially influenced by development or experience (e.g. innate noxious sensory thresholds). Thus, an infant's initial predisposition towards pain reactivity at 2 months is a significant factor in how reactive they will be at four and six months. Why this relationship did not continue at 12 months is an interesting finding. One potential suggestion is that while previous infant pain behavior did not predict 12-month reactivity but caregiver sensitivity was significant related at 12 months, that caregiver factors (for example sensitivity and actual caregiver behaviors) may be playing a larger role at the one year milestone.

Moreover, the significant smaller relationships between the infant immediate pain regulation scores (i.e. an infant's distress level 1-minute after needle) across the year, also suggests that there may be a common thread that relates this capacity over the first year of life (e.g. an innate capacity towards regulation). Thus, one could hypothesize that while previous infant regulation behavior does play a small role in determining future regulation behavior, other 
factors outside the infant (e.g. caregiver behaviors, type/intensity of pain stimulus) may play a larger role.

In conclusion, to our knowledge this is the first large-scale longitudinal examination of the interrelationships between infant pain behavior and caregiver sensitivity in an immunization context. Accordingly, there are a host of novel findings relevant to the field of infant pain. First, it is important to note that the timing of the infant pain measurement (i.e. baseline, needle, 1minute post-needle) resulted in different relationships with our caregiver measure of emotional availability and among the infant pain behaviors themselves in our sample. As asserted by previous work [18, 29], it is crucial that infant pain researchers clearly distinguish between an infant's immediate reaction to pain versus a reaction that is more related to how they recover/regulate from an acutely painful stimulus. Evidence is mounting that an infant's initial response to noxious stimuli (reactivity) is distinct from an infant's response to noxious stimuli at a more distal time point (regulation). Second, our analyses suggested that, with the exception of immediate pain reactivity to the needle across the first 6 months of life, previous infant pain behavior during baseline or regulation phases are either non-existent or minor determinants of future infant pain behavior during these same phases. Third, unlike infant pain behavior, this

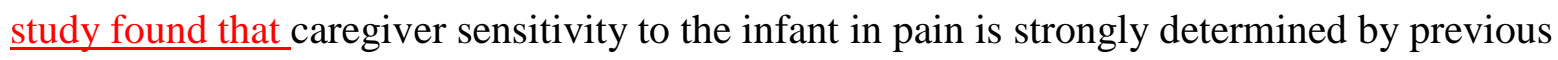
levels of sensitivity across the first year of life. Finally, the only consistent concurrent relationship between caregiver sensitivity and infant pain responses (i.e. across baseline, needle and 1-minute post needle responses) found in our analysis was seen at 12 months.

Limitations of this study. Despite the large sample size, generalizability will be affected by the education level of the sample and the self-selection bias associated with being a parent who agrees to be followed through their child's first year of immunizations. In addition, parents' 
emotional availability scores may have been impacted by being videotaped or by viewing previous video footage of their immunization appointments.

\section{Acknowledgments}

This research was supported by funds from the Canadian Institutes for Health Research (New Investigator Award to Dr. Pillai Riddell, Doctoral Award to Ms. Din Osmun; Operating Grant [PI: Pillai Riddell]), Social Sciences and Humanities Research Council (Masters award to Ms. Racine) and the Ontario Graduate Scholarship Program (Masters award to Ms. Racine). The authors have no financial interest in the results of this research. The authors would like to thank the staff at both Dr. Greenberg's and Dr. Garfield's clinic for their assistance and ongoing support.

Conflict of Interest Statement: None of the authors have any conflict of interest with this work.

\section{References}

1. Ainsworth M, Blehar, M, Waters, E, Wall, S. Patterns of attachment. Hillsdale: Lawrence Erlbaum Associates, Inc., 1978. 
2. Arbuckle, J. (1996). Full information estimation in the presence of incomplete data. In: Marcoulides,GA, Schumacker, RE, editors, Advanced structural equation modeling. Hillsdale: Lawrence Erlbaum Associates, 1996. pp. 243-278.

3. Bell R. Contributions of human infants to caregiving and social interaction. In: Lewis M, Rosenblum L, editors. The effect of the infant on its caregivers. New York: John Wiley and Sons, 1974. pp. 1-19.

4. Bigelow AE, MacLean K, Proctor J, Myatt T, Gillis R, Power M. Maternal sensitivity throughout infancy: continuity and relation to attachment security. Infant Behav Dev 2010;33:50-60.

5. Biringen Z. Emotional availability: conceptualization and research findings. Am J Orthopsychiatry 2000;70:104-114.

6. Biringen Z. The emotional availability (EA) scales, $4^{\text {th }}$ ed. Published by emotionalavailability.com 2008.

7. Blount RL, Devine KA, Cheng PS, Simons LE, Hayutin L. The impact of adult behaviors and vocalizations on infant distress during immunizations. J Pediatr Psychol 2008;16:795-809. 8. Blount RL, Piira T, Cohen LL. Management of pediatric pain and distress due to medical procedures. In: Roberts MC, editor. Handbook of pediatric psychology. $3^{\text {rd }}$ ed. New York: Guilford Press, 2003. pp. 216-233.

9. Bowlby J. Attachment and loss: Vol. 1. Attachment. New York: Basic Books, 1969/1982.

10. Bowlby J. Attachment and loss: Vol. 2. Separation. New York: Basic Books, 1973. 11. Campos RG. Rocking and pacifiers: two comforting interventions for heelstick pain. Res Nurs Health 1994;17:321-331. 
12. Cicchetti D. Fractures in the crystal: developmental psychopathology and the emergence of self. Dev Rev 1991;11:271-287.

13. Cohen LL, Manimala R, Blount RL. Easier said than done: what parents say they do and what they do during children's immunizations. Children's Health Care 2000;29:79-86.

14. Cohen LL, Bernard RS, McClellan CB, MacLaren JE. Assessing medical room behavior during infants' painful procedures: the measure of adult and infant soothing and distress (MAISD). Children's Health Care 2005;34:81-94.

15. Crockenberg S, Smith P. Antecedents of mother-infant interaction and infant irritability in the first three months of life. Infant Behav Dev 1982;5:105-119.

16. DeMore M, Cohen LL. Distraction for pediatric immunization pain: a critical review. J Clin Psychol Med Settings 2005;12:281-291.

17. De Wolff M, van IJzendoorn, MH. Sensitivity and attachment: A meta-analysis on parental antecedents of infant attachment. Child Dev 1997; 68:571-591.

18. Din L, Pillai Riddell R, Gordner S. Brief report: maternal emotional availability and infant pain-related distress. J Pediatr Psychol 2009;34:722-726.

19. Gonzalez JC, Routh DK, Armstrong FD. Effects of maternal distraction versus reassurance on children's reactions to injections. J Pediatr Psychol 1993;18:593-604.

20. Grolnick WS, Kurowski CI, McMenamy JM, Rivkin I, Bridges LJ. Mothers'strategies for regulating their toddlers' distress. Infant Behav Dev 1998;21:437-450.

21. Grunau RVE, Craig KD. Pain expression in neonates: facial action and cry. Pain $1987 ; 28: 395-410$.

22. Grunau RE, Oberlander TF, Holsti L, Whitfield MF. Bedside application of the neonatal facial coding system in pain assessment of premature neonates. Pain 1998;76:277-286. 
23. $\mathrm{Hu} \mathrm{L}, \mathrm{Bentler} \mathrm{PM}$. Fit indices in covariance structure modeling: Sensitivity to underparameterized model misspecification. Psychological Methods 1998; 3:424-453.

24. Jahromi LB, Stifter CA. Individual differences in the contribution of maternal soothing to infant distress reduction. Infancy 2007;11:255-269.

25. Kessler RC, Greenberg DF. Linear panel analysis. New York: Academic Press, 1981.

26. Oberlander TF, Grunau R, Whitfield MF, Fitzgerald C, Pitfield S, Saul JP. Biobehavioral pain responses in former extremely low birth weight infants at four months' corrected age. Pediatrics 2000;105-106.

27. Pederson DR. The soothing effect of rocking as determined by the direction and frequency of movement. Can J Behav Sci 1975;7:237-243.

28. Piira T, Champion D, Bustos T, Donnelly N, Lui K. Factors associated with infant pain response following an immunization injection. Early Hum Dev 2007;83:319-326.

29. Pillai Riddell RR, Badali MA, Craig KD. Parental judgments of infant pain: importance of perceived cognitive abilities, behavioral cues and contextual cues. Pain 2004;9:73-80.

30. Pillai Riddell RR, Chambers CT. Parenting the Infant in Pain. In: Anand, K, Stevens, B, McGrath, PJ, editors. Pain in Neonates and Infants, $3^{\text {rd }}$ Edition. Edinburgh: Elsevier Limited, 2007. pp. 289-298

31. Pillai Riddell RR, Stevens BJ, Cohen LL, Flora DB, Greenberg S. Predicting maternal and behavioral measures of infant pain: The relative contribution of maternal factors. Pain 2007; $133: 138-149$.

32. Pillai Riddell RR, Racine N. Assessing pain in infancy: the caregiver context. Pain Res Manag 2009;14:27-32.

33. Robison SD, Frick PJ, Sheffield M. Temperament and parenting: Implications for 
understanding developmental pathways to conduct disorder. Minerva Pediatr 2005; 57:373-88. 34. Sameroff A. Early influences on development: fact or fancy. Merrill Palmer Q 1975;21:267294.

35. Sander LW. Infant and caretaking environment: investigation and conceptualization of adaptive behavior in a system of increasing complexity. In: Anthony EJ, editor. Explorations in child psychiatry. New York: Plenum Press, 1975. pp. 129-166.

36. Schechter NL, Zempsky WT, Cohen LL, McGrath PJ, McMurtry CM, Bright NS. Pain reduction during pediatric immunizations: Evidence-based review and recommendations. Pediatrics 2007;119:1184-1198.

37. Sroufe A, Egeland B, Carlson E, Collins A. The development of the person: the Minnesota study of risk and adaptation from birth to adulthood. New York: The Guilford Press, 2005. 38. Stright AD, Gallager KC, Kelley K. Infant temperament moderates relations between maternal parenting in early childhood and children's adjustment in first grade. Child Dev 2008; 79:186-200.

39. Sweet SD, McGrath PJ. Relative importance of mothers' versus medical staffs' behavior in the prediction of infant immunization pain behavior. J Pediatr Psychol 1998;23:249-256. 40. Tabachnick BG, Fidell LS. Using multivariate statistics. $4^{\text {th }}$ ed. Boston: Allyn and Bacon, 2001.

41. Yuan, KH, Bentler PM. Three likelihood-based methods for mean and covariance structure analysis with nonnormal missing data. Sociol Methodol 2000;30:165-200. 
Summary:

Previous caregiver sensitivity and infant pain behaviour predict future sensitivity and behaviour in the immunization context but consistent interrelationships are not seen until 12 months of age. 
Table 1

Demographic variables

\begin{tabular}{|c|c|c|c|c|}
\hline & 2 months & 4 months & 6 months & 12 months \\
\hline \multicolumn{5}{|l|}{ Caregivers present at immunization } \\
\hline Mother & $51.4 \%$ & $62.2 \%$ & $61.0 \%$ & $55.6 \%$ \\
\hline Mother and Father & $38.6 \%$ & $29.4 \%$ & $29.9 \%$ & $27.4 \%$ \\
\hline Father & $2.2 \%$ & $1.4 \%$ & $2.6 \%$ & $9.5 \%$ \\
\hline Parent(s) and Grandparent(s) & $4.4 \%$ & $3.7 \%$ & $3.5 \%$ & $3.3 \%$ \\
\hline Other & $3.4 \%$ & $3.3 \%$ & $3.0 \%$ & $1.4 \%$ \\
\hline \multicolumn{5}{|l|}{ Self-reported heritage culture at recruitment* } \\
\hline European & $36.5 \%$ & $29.7 \%$ & $36.8 \%$ & \\
\hline Canadian/American & $13.5 \%$ & $14.1 \%$ & $5.9 \%$ & \\
\hline Asian & $20.3 \%$ & $19.5 \%$ & $17.7 \%$ & \\
\hline African/Middle Eastern & $5.7 \%$ & $4.9 \%$ & $4.4 \%$ & \\
\hline Jewish & $7.4 \%$ & $8.1 \%$ & $7.4 \%$ & \\
\hline South/Latin American & $2.6 \%$ & $5.4 \%$ & $4.4 \%$ & \\
\hline Mixed Canadian & $4.8 \%$ & $4.9 \%$ & $4.4 \%$ & \\
\hline Other & $9.2 \%$ & $13.4 \%$ & $19 \%$ & \\
\hline \multicolumn{5}{|l|}{ Education level at recruitment* } \\
\hline Graduate School or Professional Training & $30.0 \%$ & $33.5 \%$ & $27.9 \%$ & \\
\hline University Graduate & $41.8 \%$ & $36.9 \%$ & $32.4 \%$ & \\
\hline Partial University & $5.1 \%$ & $5.7 \%$ & $2.9 \%$ & \\
\hline Trade School or Community College & $15.3 \% \%$ & $15.9 \%$ & $26.5 \%$ & \\
\hline High School Graduate & $7.1 \%$ & $7.4 \%$ & $8.8 \%$ & \\
\hline Did Not Graduate from High School & $0.7 \%$ & $0.6 \%$ & $1.5 \%$ & \\
\hline \multicolumn{5}{|l|}{ Infant gender at recruitment* } \\
\hline Male & $49.1 \%$ & $46.0 \%$ & $52.0 \%$ & \\
\hline Female & $50.9 \%$ & $54.0 \%$ & $47.1 \%$ & \\
\hline
\end{tabular}

*No infants recruited at 12 months 
Table 2

Means, Standard Deviations and Correlations For Model Variables

\begin{tabular}{llrr}
\hline & N & \multicolumn{1}{l}{ Mean } & Std. Deviation \\
\hline NFCS baseline 2 months & 462 & .15 & .15 \\
NFCS needle 2 months & 462 & .78 & .18 \\
NFCS 1 minute_2 months & 462 & .34 & .27 \\
NFCS baseline_4 months & 549 & .14 & .14 \\
NFCS needle_4 months & 549 & .69 & .22 \\
NFCS 1minute_4 months & 549 & .23 & .21 \\
NFCS baseline_6 months & 537 & .17 & .19 \\
NFCS needle 6 months & 537 & .68 & .21 \\
NFCS 1 minute_6 months & 537 & .22 & .19 \\
NFCS baseline_12 months & 438 & .19 & .20 \\
NFCS needle_12 months & 438 & .69 & .24 \\
NFCS 1 minute_12 months & 436 & .31 & .22 \\
EAS Total_2 months & 310 & 90.59 & 10.72 \\
EAS Total_4 months & 357 & 93.98 & 9.18 \\
EAS Total6 months & 397 & 93.63 & 10.59 \\
EAS Total_12 months & 363 & 92.47 & 11.01 \\
\hline
\end{tabular}


Table 3 Bivariate Correlations among Model Variables (p-value in brackets)

\begin{tabular}{|c|c|c|c|c|c|c|c|c|c|c|c|c|c|c|c|c|}
\hline & $\begin{array}{l}\text { NFCS } \\
\text { Baseline } \\
2 \text { mos }\end{array}$ & $\begin{array}{l}\text { NFCS } \\
\text { Needle } \\
2 \text { mos. }\end{array}$ & $\begin{array}{l}\text { NFCS } \\
1 \mathrm{~min} \\
2 \mathrm{mos} .\end{array}$ & $\begin{array}{l}\text { NFCS } \\
\text { Baseline } \\
4 \text { mos. }\end{array}$ & $\begin{array}{l}\text { NFCS } \\
\text { Needle } \\
4 \text { mos. }\end{array}$ & $\begin{array}{l}\text { NFCS } \\
1 \mathrm{~min} \\
4 \mathrm{mos} .\end{array}$ & $\begin{array}{l}\text { NFCS } \\
\text { Baseline } \\
6 \text { mos. }\end{array}$ & $\begin{array}{l}\text { NFCS } \\
\text { Needle } \\
6 \text { mos. }\end{array}$ & $\begin{array}{l}\text { NFCS } \\
1 \mathrm{~min} \\
6 \mathrm{mos} .\end{array}$ & $\begin{array}{l}\text { NFCS } \\
\text { Baseline } \\
12 \text { mos. }\end{array}$ & $\begin{array}{l}\text { NFCS } \\
\text { Needle } \\
12 \text { mos. }\end{array}$ & $\begin{array}{l}\text { NFCS } \\
1 \mathrm{~min} \\
12 \mathrm{mos}\end{array}$ & $\begin{array}{l}\text { EAS } \\
2 \text { mos. }\end{array}$ & $\begin{array}{l}\text { EAS } \\
4 \text { mos. }\end{array}$ & $\begin{array}{l}\text { EAS } \\
6 \text { mos. }\end{array}$ & $\begin{array}{l}\text { EAS } \\
12 \text { mos. }\end{array}$ \\
\hline NFCS & 1 & $.15^{* *}$ & $.15 * *$ & .05 & $.15^{* *}$ & .10 & .03 & $.12 *$ & .06 & .08 & $-.16 * *$ & .04 & -.01 & .04 & .00 & .09 \\
\hline Base-2 & $(1.00)$ & $(.002)$ & $(.001)$ & $(.371)$ & $(.005)$ & $(.064)$ & $(.561)$ & $(.028)$ & $(.271)$ & $(.170)$ & $(.007)$ & $(.485)$ & $(.879)$ & $(.581)$ & $(.970)$ & $(.161)$ \\
\hline NFCS & & 1 & $.20 * * *$ & $.11^{*}$ & $.31 * * *$ & .04 & .09 & $.16^{* *}$ & .03 & $.17^{* *}$ & -.04 & .02 & -.04 & -.07 & .04 & .00 \\
\hline Need-2 & & & $(.000)$ & $(.038)$ & $(.000)$ & $(.402)$ & $(.094)$ & $(.005)$ & $(.554)$ & $(.004)$ & $(.567)$ & $(.800)$ & $(.478)$ & $(.290)$ & $(.511)$ & $(.952)$ \\
\hline NFCS & & & 1 & .08 & $.12 *$ & $.15^{* *}$ & -.04 & $.14^{*}$ & .06 & .04 & .05 & .01 & -.06 & .09 & .06 & .07 \\
\hline $1 \mathrm{~min}-2$ & & & & $(.147)$ & $(.018)$ & (.003) & $(.529)$ & $(.014)$ & $(.275)$ & $(.482)$ & $(.436)$ & $(.907)$ & $(.274)$ & $(.177)$ & $(.340)$ & $(.304)$ \\
\hline NFCS & & & & 1 & $.17 * * *$ & $.31 * * *$ & $.13^{* *}$ & .08 & $.15^{* * *}$ & .07 & .06 & .03 & -.11 & $-.19 * * *$ & $-.15^{* *}$ & $-.18 * *$ \\
\hline Base-4 & & & & & $(.000)$ & $(.000)$ & $(.010)$ & $(.091)$ & $(.002)$ & $(.198)$ & $(.310)$ & (.618) & $(.085)$ & $(.000)$ & $(.009)$ & $(.002)$ \\
\hline Need-4 & & & & & & $(.000)$ & $(.000)$ & $(.000)$ & $(.002)$ & $(.034)$ & $(.247)$ & $(.014)$ & $(.968)$ & $(.893)$ & $(.579)$ & $(.371)$ \\
\hline NFCS & & & & & & 1 & $.16^{* *}$ & $.13^{* *}$ & .08 & .03 & .09 & $.13 *$ & $-.13^{*}$ & $-.11 *$ & -.08 & -.08 \\
\hline $1 \mathrm{~min}-4$ & & & & & & & $(.001)$ & $(.006)$ & $(.116)$ & $(.640)$ & $(.092)$ & $(.018)$ & $(.035)$ & $(.038)$ & $(.188)$ & $(.156)$ \\
\hline NFCS & & & & & & & 1 & $.22 * * *$ & $.25 * *$ & .09 & -.01 & .09 & .03 & .00 & -.05 & .03 \\
\hline Base-6 & & & & & & & & $(.000)$ & $(.000)$ & $(.094)$ & $(.800)$ & $(.076)$ & $(.662)$ & $(.941)$ & $(.320)$ & $(.551)$ \\
\hline NFCS & & & & & & & & 1 & $.32 * * *$ & .09 & .09 & $.11 *$ & -.02 & -.03 & -.06 & -.06 \\
\hline Need-6 & & & & & & & & & $(.000)$ & $(.090)$ & $(.072)$ & $(.031)$ & $(.741)$ & $(.598)$ & $(.215)$ & $(.328)$ \\
\hline NFCS & & & & & & & & & 1 & $.20 * * *$ & -.04 & $.11 *$ & .10 & .01 & -.06 & -.01 \\
\hline $1 \min -6$ & & & & & & & & & & $(.000)$ & $(.474)$ & $(.037)$ & $(.118)$ & $(.849)$ & $(.220)$ & $(.832)$ \\
\hline NFCS & & & & & & & & & & 1 & .03 & $.16 * *$ & .06 & .05 & .04 & -.08 \\
\hline NFCS & & & & & & & & & & & 1 & $.23 * * *$ & -.08 & -.07 & -.09 & $-.16 * *$ \\
\hline Need-12 & & & & & & & & & & & & $(.000)$ & $(.217)$ & $(.237)$ & $(.123)$ & $(.002)$ \\
\hline NFCS & & & & & & & & & & & & 1 & -.05 & -.04 & -.08 & $-.19 * * *$ \\
\hline 1 min-12 & & & & & & & & & & & & & $(.414)$ & $(.538)$ & $(.184)$ & $(.000)$ \\
\hline EAS-2 & & & & & & & & & & & & & 1 & $.38 * * *$ & $.56 * * *$ & $.46 * * *$ \\
\hline & & & & & & & & & & & & & & $(.000)$ & $(.000)$ & $(.000)$ \\
\hline EAS-4 & & & & & & & & & & & & & & 1 & $\begin{array}{l}.44 * * * \\
(.000)\end{array}$ & $\begin{array}{l}.42^{* * * *} \\
(.000)\end{array}$ \\
\hline EAS-6 & & & & & & & & & & & & & & & 1 & $.62 * * *$ \\
\hline & & & & & & & & & & & & & & & & $(.000)$ \\
\hline EAS-12 & & & & & & & & & & & & & & & & 1 \\
\hline
\end{tabular}

$$
\begin{aligned}
& * \mathrm{p}<.05 \\
& * * \mathrm{p}<.01 \\
& * * * \mathrm{p}<.000
\end{aligned}
$$


Table 4

Unstandardized estimates of the relationships between caregiver sensitivity and NFCS baseline scores over the first year of life

\begin{tabular}{|c|c|c|c|c|}
\hline & Estimate & Standard Error & Est./S.E. & Two-Tailed P-Value \\
\hline \multicolumn{5}{|l|}{ NFCS baseline 12 months } \\
\hline NFCS baseline 6 months & .10 & .08 & 1.33 & .18 \\
\hline EAS 6 months & .00 & .00 & 1.14 & .26 \\
\hline \multicolumn{5}{|l|}{ EAS 12 months } \\
\hline EAS 6 months & .62 & .05 & 13.71 & .00 \\
\hline NFCS baseline 6 months & 3.90 & 2.84 & 1.37 & .17 \\
\hline \multicolumn{5}{|l|}{ NFCS baseline 6 months } \\
\hline NFCS baseline 4 months & .16 & .08 & 2.07 & .04 \\
\hline EAS 4 months & .00 & .00 & .48 & .635 \\
\hline \multicolumn{5}{|l|}{ EAS 6 months } \\
\hline EAS 4 months & .54 & .06 & 8.92 & .00 \\
\hline NFCS baseline 4 months & -3.41 & 3.83 & -.89 & .37 \\
\hline \multicolumn{5}{|l|}{ NFCS baseline 4 months } \\
\hline NFCS baseline 2 months & .05 & .05 & .96 & .34 \\
\hline EAS 2 months & -.00 & .00 & -1.69 & .09 \\
\hline \multicolumn{5}{|l|}{ EAS 4 months } \\
\hline EAS 2 months & .40 & .06 & 7.22 & .00 \\
\hline NFCS baseline 2months & -.76 & 3.58 & -.21 & .83 \\
\hline \multicolumn{5}{|l|}{ NFCS baseline 2 months } \\
\hline EAS 2 months & -.02 & .10 & -.20 & .84 \\
\hline \multicolumn{5}{|l|}{ NFCS baseline 4 months } \\
\hline EAS 4 months & -.24 & .08 & -3.13 & .00 \\
\hline \multicolumn{5}{|l|}{ NFCS baseline 6 months } \\
\hline EAS 6 months & -.10 & .10 & -.99 & .32 \\
\hline \multicolumn{5}{|l|}{ NFCS baseline 12 months } \\
\hline EAS 12 months & -.23 & .09 & -2.54 & .01 \\
\hline
\end{tabular}



Table 5

Unstandardized estimates of the relationships between caregiver sensitivity and NFCS needle scores over the first year of life

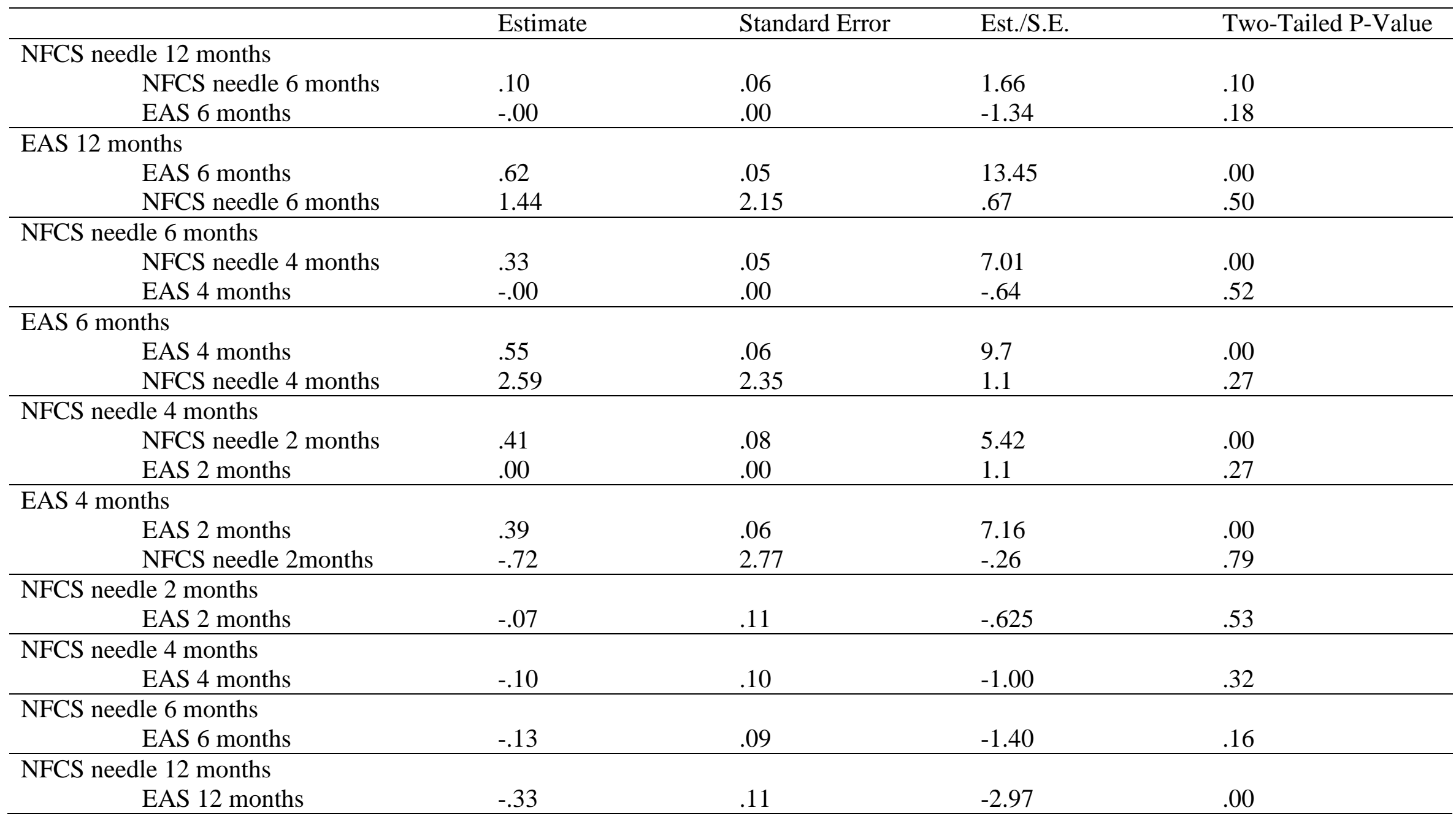



Table 6

Unstandardized estimates of the relationships between caregiver sensitivity and NFCS 1 minute scores over the first year of life

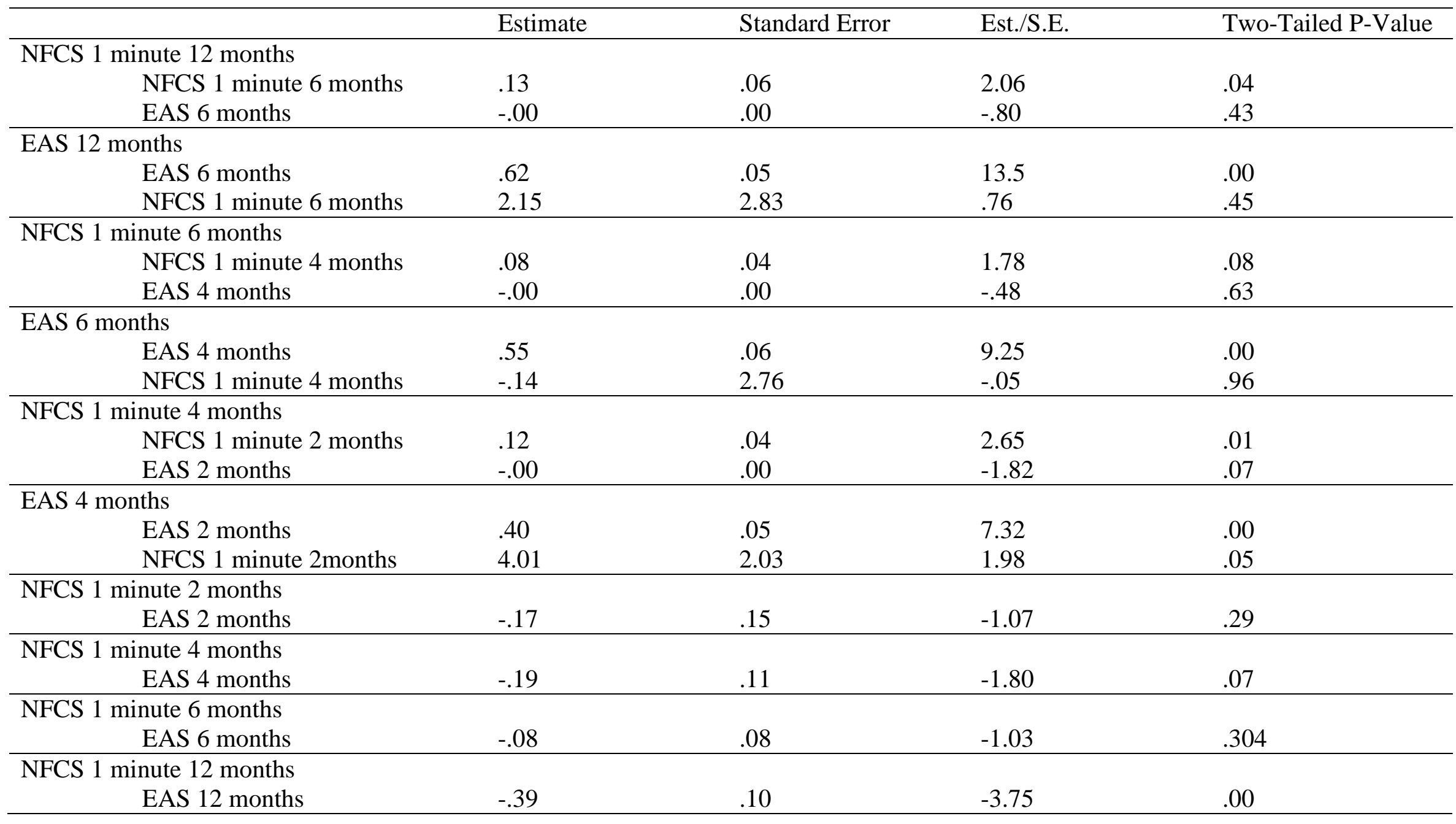





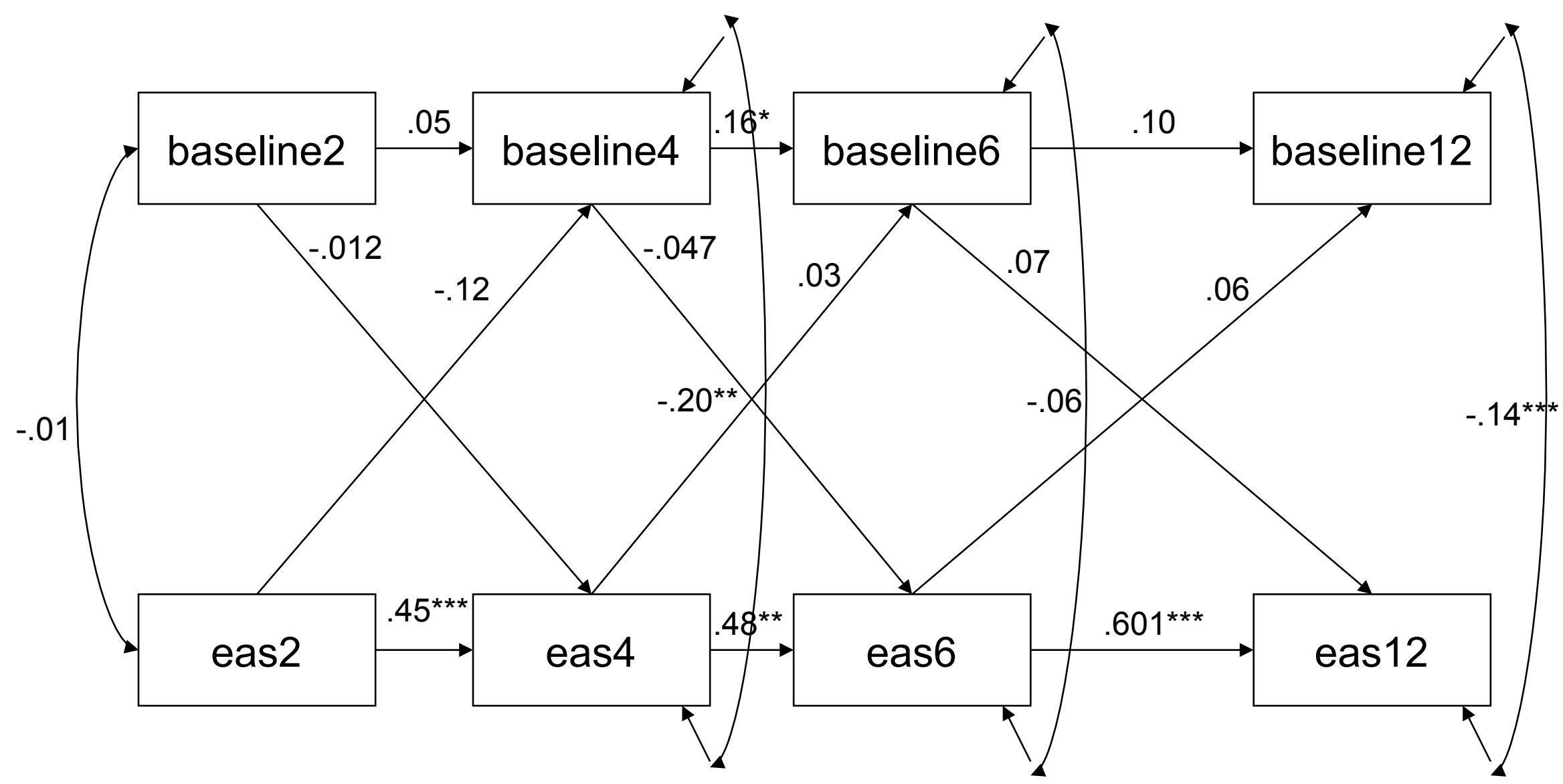

Figure 1: Standardized coefficients of the relationships between caregiver sensitivity and NFCS baseline scores over the first year of life

\footnotetext{
* Significant at $p<.05$

** Significant at $p<.01$

${ }^{* * *}$ Significant at $p<.001$
} 


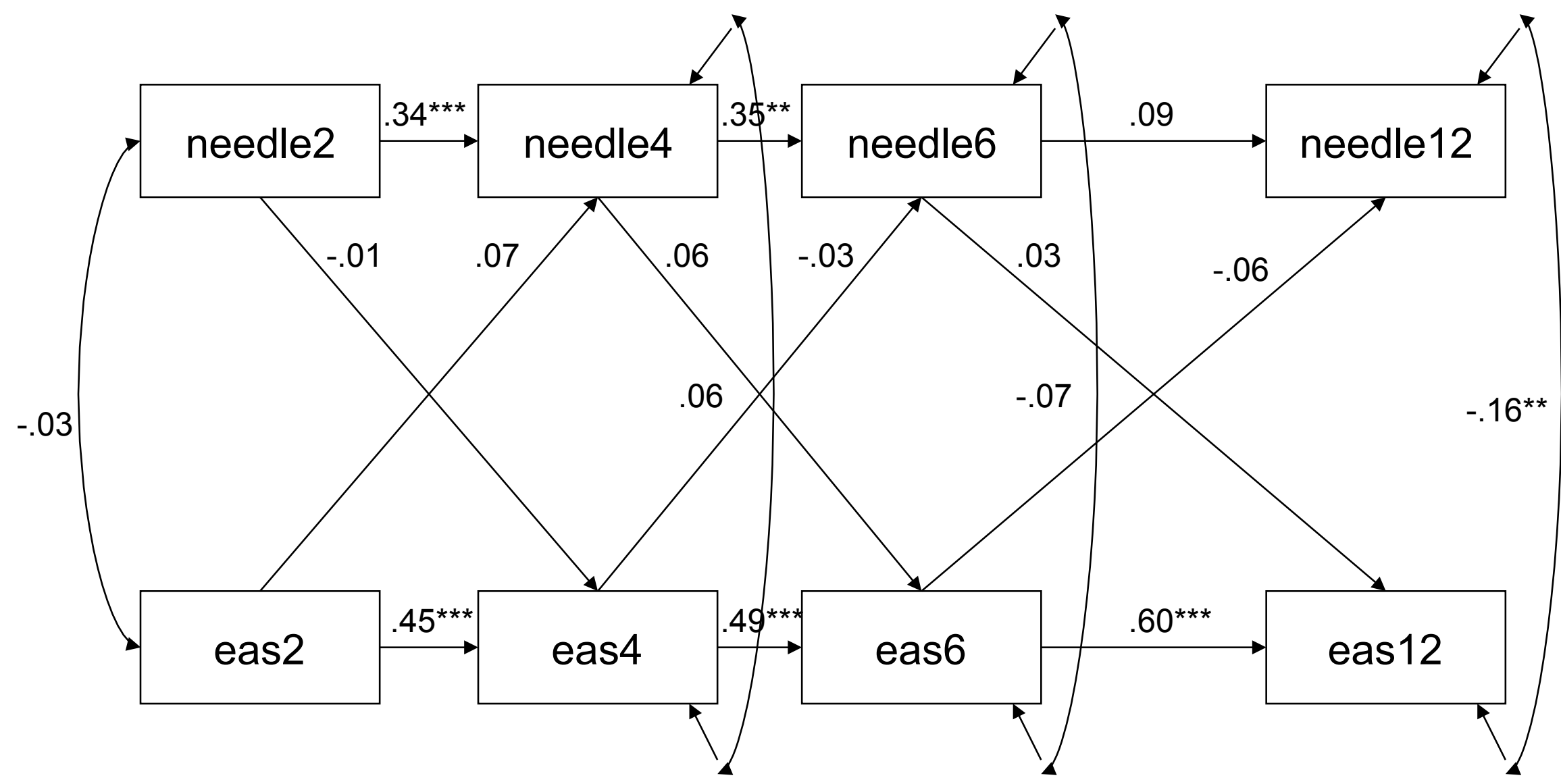

Figure 2: Standardized coefficients of the relationships between caregiver sensitivity and NFCS needle scores over the first year of life

* Significant at $p<.05$

** Significant at $p<.01$

*** Significant at $p<.001$ 


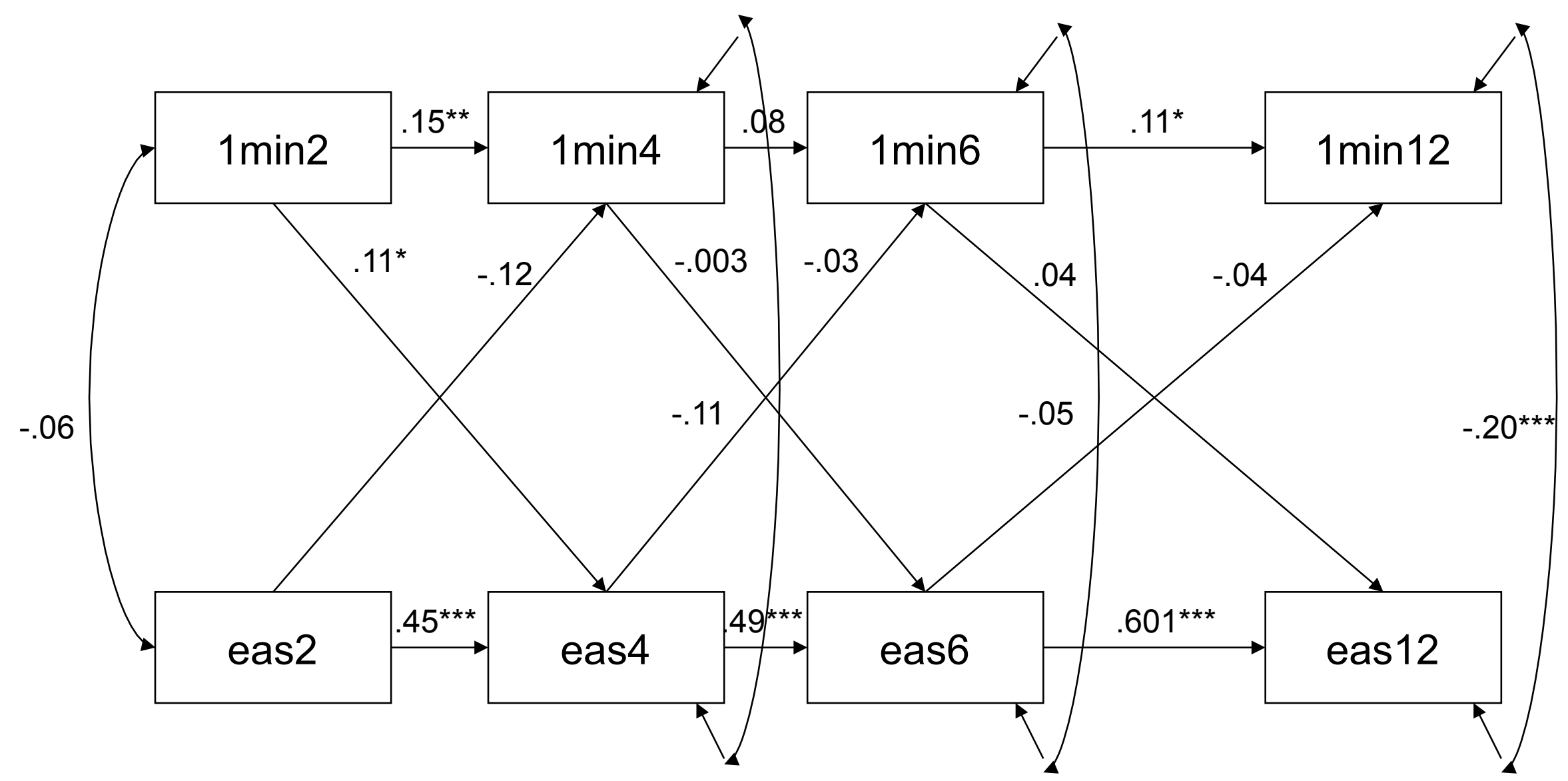

Figure 3: Standardized coefficients of the relationships between caregiver sensitivity and NFCS 1 minute scores over the first year of life

* Significant at $p<.05$

** Significant at $p<.01$

*** Significant at $p<.001$ 